\title{
(อ) OPEN ACCESS \\ Perinatal outcomes among births to women with infection during pregnancy
}

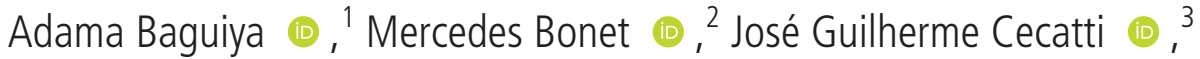

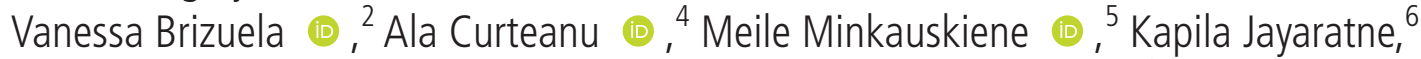 \\ Carolina Carvalho Ribeiro-do-Valle @ ${ }^{7}$ Mihaela-Alexandra Budianu, ${ }^{8}$ \\ João Paulo Souza 다, ${ }^{9}$ Séni Kouanda 다, ${ }^{10,11}$ The WHO Global Maternal Sepsis Study \\ (GLOSS) Research Group
}

\begin{abstract}
- Additional supplemental material is published online only. To view, please visit the journal online (http://dx.doi. org/10.1136/archdischild2021-321865)
\end{abstract}

For numbered affiliations see end of article.

\section{Correspondence to}

Dr Adama Baguiya, Kaya Health and Demographic Surveillance System (Kaya-HDSS), Research Institute of Health Sciences, Ouagadougou, Burkina Faso abaguiya@gmail.com

Received 15 February 2021 Accepted 9 July 2021 Published Online First 2 September 2021

Check for updates

(C) Author(s) (or their employer(s)) 2021. Re-use permitted under CC BY-NC. No commercial re-use. See rights and permissions. Published by BMJ.

To cite: Baguiya A, Bonet $M$, Cecatti JG, et al.

Arch Dis Child

2021;106:946-953.

\section{ABSTRACT}

Objective This study is part of the Global Maternal Sepsis Study (GLOSS). It aimed to estimate neonatal near-miss (NNM) and perinatal death frequency and maternal risk factors among births to women with infection during pregnancy in low-income and middleincome countries (LMIC).

Design We conducted a 1-week inception hospitalbased cohort study.

Setting The study was carried out in 408 hospitals in 43 LMIC of all the WHO regions in 2017.

Patients We included women with suspected or confirmed infection during pregnancy with at least 28 weeks of gestational age up to day-7 after birth. All babies born to those women were followed from birth until the seventh day after childbirth. Perinatal outcomes were considered at the end of the follow-up.

Main outcome measures Perinatal outcomes were (i) babies alive without severe complication, (ii) NNM and (iii) perinatal death (stillbirth and early neonatal death). Results 1219 births were analysed. Among them, $25.9 \%(n=316)$ and $10.1 \%(n=123)$ were NNM and perinatal deaths, respectively. After adjustment, maternal pre-existing medical condition (adjusted odds ratios $(\mathrm{aOR})=1.5 ; 95 \% \mathrm{Cl} 1.1$ to 2.0 ) and maternal infection suspected or diagnosed during labour $(\mathrm{aOR}=1.9 ; 95 \%$ $\mathrm{Cl} 1.2$ to 3.2) were the independent risk factors of NNM. Maternal pre-existing medical condition $(\mathrm{aOR}=1.7$; $95 \% \mathrm{Cl} 1.0$ to 2.8 ), infection-related severe maternal outcome (aOR=3.8; 95\% Cl 2.0 to 7.1$)$, mother's infection suspected or diagnosed within 24 hours after childbirth (aOR=2.2; 95\% Cl 1.0 to 4.7) and vaginal birth $(\mathrm{aOR}=1.8 ; 95 \% \mathrm{Cl} 1.1$ to 2.9$)$ were independently associated with increased odds of perinatal death.

Conclusions Overall, one-third of births were adverse perinatal outcomes. Pre-existing maternal medical conditions and severe infection-related maternal outcomes were the main risk factors of adverse perinatal outcomes.

\section{BACKGROUND}

Direct maternal infections account for $10.7 \%$ of all maternal deaths globally. ${ }^{1}$ Low-income and middle-income countries (LMIC) represent 98\% of neonatal mortality, with $79 \%$ occurring in South Asia and sub-Saharan Africa. ${ }^{2}$ More than one-third of neonatal deaths occur during the first day of life and around two-thirds within the first week. ${ }^{34}$

\section{What is already known on this topic?}

- Previous studies mainly assessed infection during pregnancy as an exposure to measure its effects on perinatal outcomes in specific diseases such as malaria, Streptococcus B, and HIV.

- There are studies on the burden of perinatal outcomes in the specific group of mothers admitted with infection, but mostly from highincome countries.

- We could not find strong evidence on maternal risk factors, and data in this specific population in low-income and middle-income countries (LMIC) are scarce.

\section{What this study adds?}

- This study provides data on perinatal outcomes in women with confirmed or suspected infection during pregnancy with global data from 43 LMIC.

- It identified maternal factors that explain why some women have 'healthy babies' and others have stillbirths, early neonatal deaths or babies with severe neonatal complications.

- These findings can help to improve newborn care as they highlight the adverse condition of fetuses and newborns in women with severe clinical status.

Among those deaths, at least one-third is related to infection, and neonatal sepsis is a major cause of infant morbidity and mortality. ${ }^{4}$ Hibberd et al estimated the incidence of possible bacterial severe neonatal infection in 2016 to be $12.9 \%$ (95\% CI $12.8 \%$ to $13.0 \%)$ ) with a case-fatality risk of $14 \%$ in sub-Saharan Africa, South Asia and Latin America. ${ }^{5}$ Although neonatal mortality declined worldwide between 1990 and 2019 by 20 deaths per 1000 live births, ${ }^{6}$ the global burden of infection-related neonatal mortality did not significantly drop, ${ }^{7}$ and the identification and management of maternal and neonatal infection are still challenging in developing countries. 


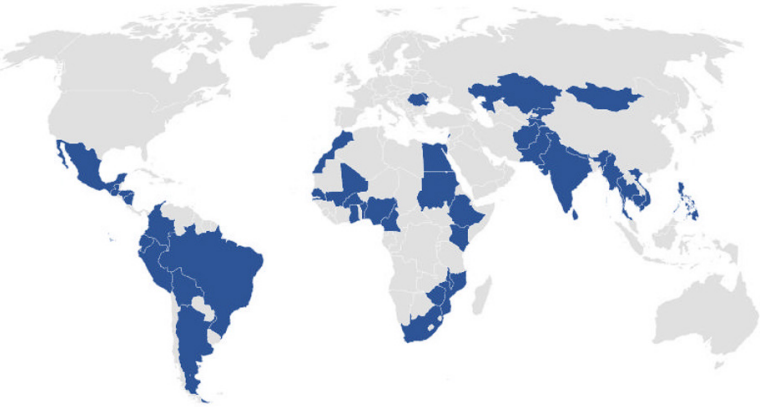

Figure 1 Map of the world showing the included countries in blue.

Infection in pregnant women has mostly been examined as exposure in a disease-specific analysis. ${ }^{8-10}$ Consequently, previous studies showed that infants born to mothers with infection during pregnancy have an increased risk of adverse perinatal outcomes (APO), including stillbirths and neonatal deaths, compared with those who did not experience a maternal infection. ${ }^{11} 12$ However, in the specific population of women with infection during pregnancy, little is known about why some have 'healthy babies', while others' pregnancies end with APO. Most of the available data are from high-income countries and often, limited samples of perinatal outcomes were examined. ${ }^{12-14}$ The WHO Global Maternal Sepsis Study (GLOSS), carried out in 52 countries, is an opportunity to provide data on the burden and risk factors of APO in this population in LMIC. ${ }^{15}$ Therefore, we aimed to determine the frequency and maternal risk factors of APO among births from women with suspected or confirmed infection during pregnancy in LMIC.

\section{METHODS}

Study design and participants

We included data from 43 LMICs participating in GLOSS, based on the World Bank classification, ${ }^{16}$ representing all of the six WHO regions. GLOSS was a hospital-based, prospective, 1-week inception cohort study. ${ }^{16}$ Figure 1 shows the map of the countries involved in the study. Detailed information on the study participants and procedures can be found elsewhere. ${ }^{17}$ Briefly, GLOSS included all women admitted or already hospitalised for at least 12 hours during the study identification week (28 November to 4 December 2017), with suspected or confirmed infection at any stage of pregnancy, up to the $42 \mathrm{nd}$ day after abortion or childbirth in participating health facilities, in purposively selected geographical areas. Information on perinatal outcomes was collected for all births up to the seventh day after childbirth, discharge or death, whichever occurred first.

We excluded all pregnancies that ended before 28 weeks of gestational age $\mathrm{and}^{18}$ and women for whom the infection was suspected or confirmed after the seventh day postpartum.

\section{Outcome variable}

The outcome variable was perinatal outcome evaluated at the end of follow-up, with three categories, which were (1) alive without severe complication, (2) neonatal near-miss (NNM) and (3) perinatal death. Perinatal death included early neonatal death (within 7 days after childbirth) and stillbirth (fresh or macerated). We applied the WHO definition of stillbirths ${ }^{19}$ and used the definition of NNM suggested by Santos et al and Pileggi-Castro et $a l^{20} 21$ (table 1). Babies alive without severe complications were born alive and did not experience any severe neonatal complication and were still alive at the end of follow-up.

\section{Independent variables}

Covariates included selected women's demographic, obstetric and clinical characteristics. Demographic characteristics were mother's age (in years), living with partner or spouse (yes/no) and schooling (in years). Obstetric factors were the number of previous births (none, one or more), other obstetric complications (none, any additional complication) and the final mode of birth (spontaneous/instrumental vaginal or caesarean section). Clinical characteristics included pre-existing maternal medical condition (none or any condition), the severity of the infectionrelated maternal outcome (less severe infection, infection-related complications and infection-related severe maternal outcome, which included maternal death and near-miss) as defined by the WHO Global Maternal Sepsis Study (GLOSS) Research Group ${ }^{15}$ pregnancy status at the time of suspicion or confirmation of the infection (during pregnancy, during labour, within 24 hours, between 24 and 72 hours and after 72 hours after childbirth), location at the time of suspicion or confirmation of the infection (arrived from home, referred by another facility, already hospitalised at the start of the study) and the source of infection (chorioamnionitis, endometritis, urinary tract infection, skin, wound, catheter infection and other infections).

Potential contextual factors were considered for adjustment. These included the country level of income (upper middleincome, lower middle-income and low-income) as defined by the World Bank in 2019, ${ }^{16}$ the WHO region (for Asia which we

\begin{tabular}{lccl}
\hline Table 1 & Criteria for the definition of neonatal near-miss cases ${ }^{2021}$ & \\
\hline Any of the pragmatic and management criteria is enough to define a neonatal near-miss case within the first week after birth \\
\hline $\mathrm{n \#}$ & Pragmatic criteria & $n \#$ & Management criteria \\
\hline 1 & Birthweight $<1750$ grams & 1 & Use of parenteral antibiotics \\
\hline 2 & Gestational age at birth between 28 and 33 weeks & 2 & Ventilation (use of nasal continuous positive airway pressure or invasive support) \\
\hline 3 & 5 min APGAR score $<7$ & 4 & Intubation at birth \\
\hline & 5 & Use of phototherapy within the first 24 hours after birth \\
& 6 & Cardiopulmonary resuscitation \\
\hline & 7 & Use of any vasoactive drug \\
& 8 & Use of anticonvulsants \\
& 9 & Administration of surfactant \\
& 10 & Administration of blood product \\
\hline
\end{tabular}


combined two regions (South Eastern Asia and Western Pacific)), the level of care (tertiary, secondary or primary), the type of health facility administration (public or private) and the number of births in 2016.

\section{Data source and collection}

GLOSS data were collected at the facility and individual women level with standardised tools. Each participating hospital completed the facility form, which provided information on hospitals' characteristics. Individual women form collected data on demographic, obstetric, clinical characteristics and information on the infections and the management during their stay in the health facility and information used to define perinatal outcomes. Infections could be confirmed using clinical examination alone or complemented by a radiological, laboratory or microbiological finding. Suspicion or confirmation of infection was undertaken as part of standard routine care in health facilities. A comprehensive description of the study procedures and measurements is available in the protocol and the previous paper of GLOSS. ${ }^{15} 17$

\section{Statistical analysis}

We computed the proportion of NNM and perinatal deaths and their rate per 1000 live births with a 95\% CI. We then fitted a mixed effects multinomial logistic regression model to examine the relationship between maternal characteristics and APO. In all the analyses, the category of babies born alive without severe neonatal complications was the outcome variable reference category. We first assessed the effects of the characteristics with crude ORs taking into account the country level clustering of the data in simple multinomial logistic regression models. We then fitted a two-level hierarchical multiple multinomial logistic regression model to estimate the adjusted odds ratios (aOR) with their $95 \% \mathrm{CI}^{22}$ The first level of this hierarchical model referred to maternal characteristics of each birth and the second level was the hospital and country-level variables. We used the intraclass correlation coefficient to assess the relevance of the multilevel analysis. The final model was selected using a stepwise approach based on the assessment of the Bayesian Information Criteria (BIC) and Akaike Information Criteria (AIC). In the null model, the AIC and BIC were 2055.5 and 2076.0, respectively. They dropped to 1763.7 and 1893.6, respectively, in the first model, which only included level of care as the hospital-level adjustment factor and 1747.8 and 1927.6 , respectively, in the final model that controlled for country income level and the number of births. Based on the AIC, we considered that the final model fits the best. Furthermore, we performed a subanalysis using the final model with confirmed cases only $(n=933)$. However, that analysis identified the same factors and did not significantly change the ORs; hence we did not present those results.

All statistical analyses were performed using Stata V.15.1 (Stata 2017: Release 15. College Station, Texas, USA).

\section{Ethical considerations}

Women were screened and included by the hospital teams. Data were extracted from medical records and no interaction was required with the women. The participants' identification data were kept confidential. Depending on the country's regulations

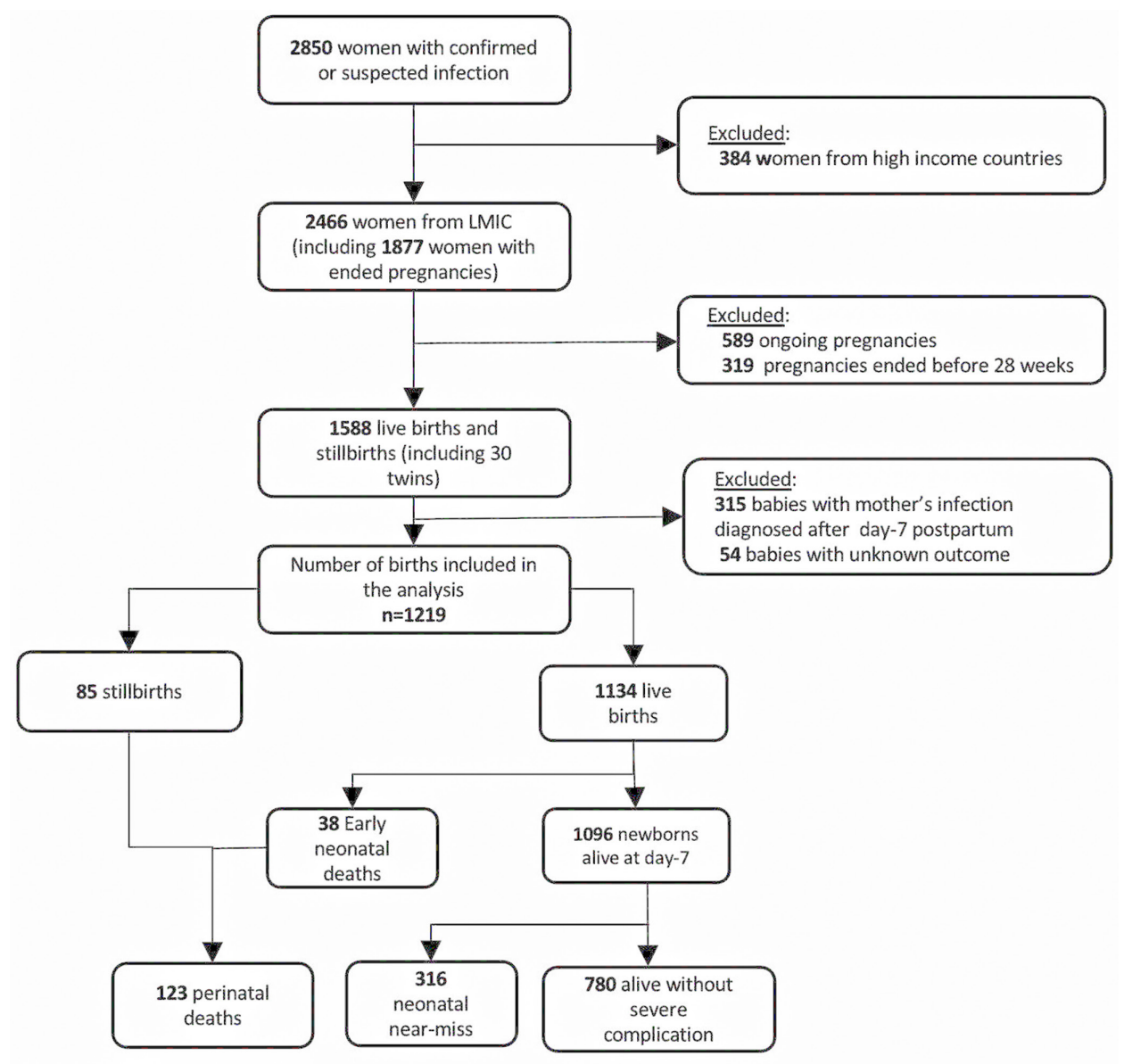

Figure 2 Flowchart of the study. LMIC, low-income and middle-income countries. 
Table 2 Percentage and rate of perinatal outcomes per 1000 live births from women with infection during pregnancy, by the country level of income

\begin{tabular}{|c|c|c|c|c|c|c|c|c|c|c|c|c|}
\hline \multirow[b]{3}{*}{ Perinatal outcomes } & \multirow{2}{*}{\multicolumn{3}{|c|}{$\begin{array}{l}\text { Total } \\
(n=1219)\end{array}$}} & \multicolumn{3}{|c|}{ Low income } & \multirow{2}{*}{\multicolumn{3}{|c|}{$\begin{array}{l}\text { Lower middle income } \\
(n=593)\end{array}$}} & \multirow{2}{*}{\multicolumn{3}{|c|}{$\begin{array}{l}\text { Upper middle income } \\
(\mathrm{n}=381)\end{array}$}} \\
\hline & & & & \multicolumn{3}{|c|}{$(n=245)$} & & & & & & \\
\hline & $\mathrm{N}$ & $\%$ & $\begin{array}{l}\text { Rate per } \\
1000 \text { live births }\end{array}$ & $\mathrm{N}$ & $\%$ & $\begin{array}{l}\text { Rate per } \\
1000 \text { live births }\end{array}$ & $\mathrm{N}$ & $\%$ & $\begin{array}{l}\text { Rate per } \\
1000 \text { live births }\end{array}$ & $\mathrm{N}$ & $\%$ & $\begin{array}{l}\text { Rate per } \\
1000 \text { live births }\end{array}$ \\
\hline $\begin{array}{l}\text { Alive without severe } \\
\text { complication }\end{array}$ & 780 & 64.0 & & 153 & 62.4 & & 351 & 59.2 & & 276 & 72.4 & \\
\hline Neonatal near-miss* & 316 & 25.9 & 278.7 (224.9-332.4) & 52 & 21.2 & $238.5(151.7-325.3)$ & 172 & 29.0 & $317.9(245.7-390.2)$ & 92 & 24.1 & $245.3(160.2-330.5)$ \\
\hline Perinatal death & 123 & 10.1 & $108.5(64.9-152.0)$ & 40 & 16.3 & $183.5(80.8-286.2)$ & 70 & 11.8 & $129.4(78.8-180.0)$ & 13 & 3.4 & $34.7(11.2-58.2)$ \\
\hline Early neonatal death & 38 & 3.1 & $33.5(20.2-46.8)$ & 13 & 5.3 & $59.6(24.4-94.8)$ & 18 & 1.5 & $33.3(18.4-48.2)$ & 7 & 1.8 & $18.7(3.4-33.9)$ \\
\hline Stillbirth & 85 & 7.0 & $75.0(41.0-108.9)$ & 27 & 11.0 & $123.9(45.4-202.3)$ & 52 & 4.3 & $96.1(52.7-139.6)$ & 6 & 1.6 & $16.0(5.0-27.0)$ \\
\hline Fresh stillbirth & 34 & 2.8 & $30.0(14.7-45.2)$ & 12 & 4.9 & $55.0(23.0-87.1)$ & 20 & 1.6 & $37.0(16.4-57.5)$ & 2 & 0.5 & $5.3(2.9-13.6)$ \\
\hline $\begin{array}{l}\text { Macerated } \\
\text { stillbirth }\end{array}$ & 51 & 4.2 & $45.0(21.4-68.5)$ & 15 & 6.1 & $68.8(3.2-140.8)$ & 32 & 2.6 & $59.1(29.7-88.6)$ & 4 & 1.0 & $10.7(2.8-18.5)$ \\
\hline
\end{tabular}

*Based on criteria presented in table 1 .

and local Institutional Review Boards (IRB), the need for informed consent was waived or sought and obtained from the participants or their caregivers if the former was unconscious. Each site also submitted the protocol to its national or institutional ethics committee for approval before data collection.

\section{RESULTS}

We included 408 hospitals, including 317 (77.7\%) located in an urban area. Tertiary and secondary level hospitals represented $38.7 \%(n=158)$ and $44.1 \%(n=180)$ of the sample, respectively (online supplemental appendix 1). These facilities were from 43 LMIC: 13 in Africa, 9 in Asia (South-East Asia and Western Pacific), 6 in Eastern Mediterranean, 5 in Europe and 10 in the Americas. The list of the countries involved is presented in online supplemental appendix 2. A total of 1219 births were analysed.
Figure 2 shows the flowchart of the study. Overall, 276 babies born alive were suspected of having an early neonatal infection, including 199 NNM and 20 perinatal deaths.

\section{Neonatal near-miss}

Among all NNM cases, $42 \cdot 7 \%(n=135)$ met the pragmatic criteria, including $29.7 \%(n=84)$ who had a gestational age between 28 and 33 weeks, and $82.6 \%(n=261)$ met the management criteria. $61 \cdot 1 \%(n=193)$ of the near-miss cases were treated with parenteral antibiotics, and $20.3 \%(n=64)$ had phototherapy within 24 hours after birth (online supplemental appendix 3).

The overall percentage of NNM was $25.9 \%(n=316 ; 95 \%$ CI 23.5 to 28.5 ) of all births, and the intrahospital rate was 278.7 (224.9 to 332.4) cases per 1000 live births (table 2). The rates and percentages were not significantly different across countries

Table 3 Perinatal outcomes of births from women with infection during pregnancy by maternal demographic and obstetric characteristics

\begin{tabular}{|c|c|c|c|c|c|c|c|c|c|}
\hline \multirow[b]{2}{*}{ Variables } & \multirow{2}{*}{$\begin{array}{l}\text { Alive without severe } \\
\text { complication }(\mathrm{n}=780)\end{array}$} & \multicolumn{4}{|c|}{$\begin{array}{l}\text { Neonatal near-miss } \\
(n=316)\end{array}$} & \multicolumn{4}{|c|}{$\begin{array}{l}\text { Perinatal death } \\
(n=123)\end{array}$} \\
\hline & & $\mathrm{n}(\%)$ & OR & $95 \% \mathrm{Cl}$ & $p$ value & n (\%) & $\mathrm{OR}$ & $95 \% \mathrm{Cl}$ & $p$ value \\
\hline \multicolumn{10}{|l|}{ Age (years) } \\
\hline$<20$ & $101(60.5)$ & $48(28.7)$ & 1.2 & 0.8 to 1.7 & 0.385 & $18(10.8)$ & 1.2 & 0.7 to 2.2 & 0.522 \\
\hline $20-35$ & $553(64.6)$ & $222(25.9)$ & ref & & & $81(9.5)$ & & & \\
\hline 35 and more & $122(65.6)$ & $42(22.6)$ & 0.9 & 0.6 to 1.3 & 0.430 & $22(11.8)$ & 1.2 & 0.7 to 2.1 & 0.438 \\
\hline \multicolumn{10}{|l|}{ Living with partner/spouse } \\
\hline No & $78(67.2)$ & $26(22.4)$ & ref & & & $12(10.3)$ & ref & & \\
\hline Yes & $672(64.5)$ & $266(25.5)$ & 1.2 & 0.8 to 1.8 & 0.393 & $104(10.0)$ & 1.0 & 0.5 to 2.1 & 0.987 \\
\hline \multicolumn{10}{|l|}{ Schooling (years) } \\
\hline Less than 5 & $103(54.8)$ & $47(25.0)$ & ref & & & $38(20.2)$ & ref & & \\
\hline $5-11$ years & $329(64.9)$ & $138(27.2)$ & 1.2 & 0.5 to 2.8 & 0.747 & $40(7.9)$ & 0.4 & 0.2 to 0.8 & $0.003^{*}$ \\
\hline 12 or more & $108(68.8)$ & $40(25.5)$ & 1.1 & 0.5 to 2.7 & 0.789 & $9(5.7)$ & 0.2 & 0.1 to 0.5 & 0.001 * \\
\hline \multicolumn{10}{|l|}{ Number of previous births } \\
\hline 0 & $237(64.1)$ & $87(23.5)$ & ref & & & $46(12.4)$ & ref & & \\
\hline 1 or more & $534(63.8)$ & $226(27.0)$ & 0.9 & 0.6 to 1.2 & 0.401 & $77(9.2)$ & 1.4 & 0.9 to 2.1 & 0.206 \\
\hline \multicolumn{10}{|l|}{ Other obstetric complicationst } \\
\hline Any additional complication & $279(56.5)$ & $141(28.5)$ & 1.4 & 1.0 to 2.0 & $0.026^{*}$ & $74(15.0)$ & 2.7 & 1.6 to 4.5 & $0.000^{*}$ \\
\hline None & $501(69.1)$ & $175(24.1)$ & ref & & & $49(6.8)$ & ref & & \\
\hline \multicolumn{10}{|l|}{ The final mode of birth } \\
\hline Vaginal (spontaneous/instrumental) $\ddagger$ & $327(63.3)$ & $127(24.6)$ & 0.9 & 0.6 to 1.4 & 0.716 & $63(12.2)$ & 1.6 & 1.0 to 2.5 & 0.069 \\
\hline Caesarean-section & $444(64.7)$ & $187(27.3)$ & ref & & & $55(8.0)$ & ref & & \\
\hline
\end{tabular}

*Statistically significant $(p<0.05)$.

tIncludes haemorrhage, hypertensive and thromboembolic disorders, dystocia, trauma during childbirth, anaesthesia, and surgery-related complications. ‡Instrumental: 35 cases. 
Table 4 Perinatal outcomes of births from women with infection during pregnancy by maternal clinical characteristics

\begin{tabular}{|c|c|c|c|c|c|c|c|c|c|}
\hline \multirow[b]{2}{*}{ Variables } & \multirow{2}{*}{$\begin{array}{l}\begin{array}{l}\text { Alive without severe } \\
\text { complication }(n=780)\end{array} \\
n(\%)\end{array}$} & \multicolumn{4}{|c|}{$\begin{array}{l}\text { Neonatal near-miss } \\
(n=316)\end{array}$} & \multicolumn{4}{|c|}{$\begin{array}{l}\text { Perinatal death } \\
(n=123)\end{array}$} \\
\hline & & n (\%) & OR & $95 \% \mathrm{Cl}$ & $p$ value & n (\%) & OR & $95 \% \mathrm{Cl}$ & $p$ value \\
\hline \multicolumn{10}{|l|}{ Pre-existing medical condition* } \\
\hline None & $386(67.4)$ & $141(24.6)$ & ref & & & $45(7.9)$ & ref & & \\
\hline Any of the medical conditions & $353(60.8)$ & $163(28.1)$ & 1.3 & 0.8 to 2.0 & 0.318 & $65(11.2)$ & 1.6 & 1.0 to 2.4 & $0.036 t$ \\
\hline \multicolumn{10}{|l|}{ Body mass index } \\
\hline$<25$ & $172(65.6)$ & $65(24.8)$ & 1.1 & 0.7 to 1.8 & 0.617 & $25(9.5)$ & 2.6 & 1.3 to 5.0 & $0.005 t$ \\
\hline $25-29$ & $200(66.5)$ & $80(26.6)$ & 1.2 & 0.8 to 1.7 & 0.371 & $21(7.0)$ & 1.9 & 0.9 to 4.1 & 0.120 \\
\hline 30 or more & $178(71.8)$ & $60(24.2)$ & ref & & & $10(4.0)$ & ref & & \\
\hline \multicolumn{10}{|l|}{ Severity of maternal infection } \\
\hline Less severe infection & $549(67.4)$ & $206(25.3)$ & ref & & & $59(7.3)$ & ref & & \\
\hline Infections with complication & $151(66.8)$ & $54(23.9)$ & 0.9 & 0.6 to 1.5 & 0.839 & $21(9.3)$ & 1.3 & 0.7 to 2.4 & 0.401 \\
\hline $\begin{array}{l}\text { Infection-related severe maternal } \\
\text { outcome }\end{array}$ & $80(44.7)$ & $56(31.3)$ & 1.9 & 1.1 to 3.1 & $0.014 \dagger$ & $43(24.0)$ & 5.0 & 2.7 to 9.3 & $0.000+$ \\
\hline \multicolumn{10}{|c|}{ Pregnancy status at the time of infection suspected or confirmed } \\
\hline Pregnant, not in labour & $153(62.5)$ & $67(27.4)$ & 1.4 & 0.8 to 2.3 & 0.216 & $25(10.2)$ & 1.4 & 0.6 to 3.3 & 0.426 \\
\hline Pregnant, in labour & $172(60.4)$ & $90(31.6)$ & 1.7 & 0.8 to 3.5 & 0.189 & $23(8.1)$ & 1.2 & 0.5 to 2.9 & 0.764 \\
\hline Postpartum within 24 hours & $162(61.4)$ & $69(26.1)$ & 1.3 & 0.8 to 2.3 & 0.286 & $33(12.5)$ & 1.8 & 0.9 to 3.6 & 0.124 \\
\hline Postpartum $24-72$ hours & $130(69.9)$ & $40(21.5)$ & 1.0 & 0.7 to 1.4 & 0.869 & $16(8.6)$ & 1.1 & 0.5 to 2.2 & 0.877 \\
\hline Postpartum after 72 hours & $129(69.7)$ & $41(22.2)$ & ref & & & $15(8.1)$ & ref & & \\
\hline \multicolumn{10}{|c|}{ Location at the time of infection suspected or confirmed } \\
\hline Arriving from home & $321(71.6)$ & $95(21.2)$ & ref & & & $32(7.1)$ & ref & & \\
\hline Transferred from another facility & $79(47.9)$ & $59(35.8)$ & 2.5 & 1.4 to 4.5 & $0.002 \dagger$ & $27(16.4)$ & 3.4 & 1.6 to 7.2 & $0.001 \dagger$ \\
\hline Already hospitalised & $378(62.7)$ & $162(26.9)$ & 1.5 & 1.0 to 2.1 & $0.046 t$ & $63(10.5)$ & 1.7 & 1.0 to 2.9 & 0.069 \\
\hline \multicolumn{10}{|l|}{ Source of infection§ } \\
\hline Chorioamnionitis & $125(48.8)$ & $97(37.9)$ & 2.4 & 1.3 to 4.6 & $0.009+$ & $34(13.3)$ & 4.3 & 1.9 to 9.8 & $0.001 \dagger$ \\
\hline Endometritis & $89(59.7)$ & $36(24.2)$ & 1.3 & 0.7 to 2.2 & 0.463 & $24(16.1)$ & 4.2 & 1.6 to 10.9 & $0.003 \dagger$ \\
\hline Urinary tract infection & $157(72.0)$ & $51(23.4)$ & ref & & & $10(4.6)$ & ref & & \\
\hline Skin, wound and catheter infection & $91(81.3)$ & $17(15.2)$ & 0.6 & 0.3 to 1.2 & 0.152 & $4(3.6)$ & 0.7 & 0.2 to 2.1 & 0.521 \\
\hline Other infection & $116(58.9)$ & $52(26.4)$ & 1.4 & 0.8 to 2.5 & 0.277 & $29(14.7)$ & 3.9 & 1.8 to 8.7 & $0.001 \dagger$ \\
\hline
\end{tabular}

*Includes anaemia, diabetes, HIV or any disease that required corticotherapy, chemotherapy, immunotherapy or transfusion during the pregnancy.

tStatistically significant $(p<0.05)$.

¥Severe maternal outcome defined as infection-related maternal death or near-miss.

$\S$ Source of infection clinically, radiologically or microbiologically confirmed.

levels of income (online supplemental appendix 4) and the WHO regions.

The maternal factors that were significantly associated with NNM in the unadjusted analysis were other obstetric complications (OR=1.4; 95\% CI 1.0 to 2.0) (table 3), infectionrelated severe maternal outcome $(\mathrm{OR}=1.9 ; 95 \% \mathrm{CI} 1.1$ to 3.1$)$, maternal transfer from another facility $(\mathrm{OR}=2.5 ; 95 \% \mathrm{CI} 1.4$ to $4.5)$, the fact that the mother was already hospitalised at the start of the study ( $\mathrm{OR}=1.5 ; 95 \% \mathrm{CI} 1.0$ to 2.1 ) and chorioamnionitis $(\mathrm{OR}=2.4 ; 95 \%$ CI 1.3 to 4.6 ) (table 4$)$.

After adjustment, only pre-existing medical conditions $(\mathrm{aOR}=1.5 ; 95 \% \mathrm{CI} 1.1$ to 2.0$)$ and infections suspected or diagnosed during labour (aOR=1.9; 95\% CI 1.2 to 3.2 ) were independently associated with higher odds of NNM (table 5).

\section{Perinatal death}

The overall proportion of perinatal deaths was $10.1 \%(n=123$; 95\% CI 8.5 to 11.9 ) (table 2). The intrahospital rate of perinatal death was 108.5 (64.9 to 152.0) deaths per 1000 live births, with a variation across countries levels of income: 183.5 (80.8 to 286.2), 129.4 (78.8 to 180.0 ) and 34.7 (11.2 to 58.2) deaths per 1000 in low-income, lower middle-income and upper middle-income countries, respectively. Among these deaths, 85 were stillbirths, including $34(40.0 \%)$ of fresh stillbirths.
After stratification by country income level, the percentages of perinatal deaths were $16.3 \%, 11.8 \%$ and $3.4 \%$ of all births in low-income, lower middle-income and upper middle-income countries, respectively (online supplemental appendix 4). The percentages in the WHO region are presented in online supplemental appendix 5 .

Online supplemental appendix 6 shows the crude ORs of the relationship between pregnancy outcomes and country and hospital characteristics. Tables 3 and 4 show crude ORs of sociodemographic, obstetric and clinical factors.

We observed in the final model that pre-existing medical conditions (aOR $=1.7 ; 95 \%$ CI 1.0 to 2.8$)$, infection-related severe maternal outcomes $(\mathrm{aOR}=3.8 ; 95 \% \mathrm{CI} 2.0$ to 7.1$)$, infection suspected or diagnosed within 24 hours after childbirth $(\mathrm{aOR}=2.2 ; 95 \% \mathrm{CI} 1.0$ to 4.7$)$ and vaginal birth $(\mathrm{aOR}=1.8$; $95 \%$ CI 1.1 to 2.9 ) were the factors independently associated with increased odds of perinatal death (table 5).

\section{DISCUSSION}

This study adds to previous efforts in estimating the burden of NNM and perinatal death ${ }^{11}$ using global data in the specific population of women with confirmed or suspected infection during pregnancy in LMIC. We showed that one-third of the births were APO (25\% were NNM and 10\% were either stillbirth 
Table 5 Maternal factors independently associated with neonatal near-miss and perinatal death from women with infection during pregnancy

\begin{tabular}{|c|c|c|c|c|c|c|}
\hline \multirow[b]{2}{*}{ Variable } & \multicolumn{3}{|c|}{$\begin{array}{l}\text { Neonatal near-miss } \\
(\mathrm{n}=316)\end{array}$} & \multicolumn{3}{|c|}{$\begin{array}{l}\text { Perinatal death } \\
(n=123)\end{array}$} \\
\hline & aOR & $95 \% \mathrm{Cl}$ & p value & aOR & $95 \% \mathrm{Cl}$ & $\mathrm{p}$ value \\
\hline \multicolumn{7}{|l|}{ Maternal pre-existing condition* } \\
\hline None & ref & & & ref & & \\
\hline Any pre-existing condition & 1.5 & 1.1 to 2.0 & $0.023 \dagger$ & 1.7 & 1.0 to 2.8 & $0.041 \dagger$ \\
\hline \multicolumn{7}{|l|}{ Severity of maternal infection $\ddagger \ddagger$} \\
\hline Less severe infection & ref & & & ref & & \\
\hline Infections with complication & 0.9 & 0.6 to 1.4 & 0.716 & 1.0 & 0.5 to 1.9 & 0.904 \\
\hline Infection-related severe maternal outcome & 1.5 & 0.9 to 2.4 & 0.099 & 3.8 & 2.0 to 7.1 & $<0.001 \dagger$ \\
\hline \multicolumn{7}{|c|}{ Pregnancy status at the time of infection suspected or confirmed } \\
\hline Pregnant not in labour & 1.5 & 0.9 to 2.6 & 0.100 & 1.7 & 0.8 to 3.8 & 0.199 \\
\hline Pregnant in labour & 1.9 & 1.2 to 3.2 & $0.011 \dagger$ & 1.2 & 0.5 to 2.9 & 0.610 \\
\hline Postpartum within 24 hours & 1.5 & 0.9 to 2.5 & 0.136 & 2.2 & 1.0 to 4.7 & $0.045 t$ \\
\hline Postpartum 24-72 hours & 1.0 & 0.6 to 1.7 & 0.964 & 0.9 & 0.4 to 2.7 & 0.905 \\
\hline Postpartum more than 72 hours & ref & & & ref & & \\
\hline \multicolumn{7}{|l|}{ Other obstetric complications } \\
\hline None & ref & & & ref & & \\
\hline Any complication & 1.3 & 0.9 to 1.8 & 0.104 & 1.7 & 1.0 to 2.8 & 0.055 \\
\hline \multicolumn{7}{|l|}{ The final mode of birth } \\
\hline Vaginal (spontaneous/instrumental) & 0.9 & 0.7 to 1.2 & 0.461 & 1.8 & 1.1 to 2.9 & $0.022 \dagger$ \\
\hline C-section & ref & & & ref & & \\
\hline
\end{tabular}

Random effect: country-level variance of the variance component model: 0.3 with $95 \% \mathrm{Cl}(0.1$ to 0.6$)$ and an intraclass correlation coefficientof $13 \%$.

Random effect: country-level variance of the final model: 0.6 with $95 \% \mathrm{Cl}(0.3$ to 1.2$)$ with an intraclass correlation coefficient of $20 \%$.

*Includes anaemia, diabetes, HIV or any disease that required corticotherapy, chemotherapy, immunotherapy or transfusion during the pregnancy.

tStatistically significant $(\mathrm{p}<0.05)$.

fInfections with complications include an invasive procedure to treat the source of infection (vacuum aspiration, dilatation and curettage, wound debridement, drainage

(incision, percutaneous, culdotomy) laparotomy, lavage and other surgery), admission to intensive care or high dependency unit or transfer to another facility. Severe maternal outcome defined as infection-related maternal death or near-miss

aOR, adjusted OR for country-level clustering (level 2 in the model), with the country and hospital-level factors (country income level, hospital level of care and number of births in 2016) in the multilevel multinomial logistic regression model.; ICC, intraclass correlation coefficient .

or early neonatal death). The perinatal death rate was 108.5 per 1000 live births. Although we do not have previous data for comparison, these proportions are high compared with recent estimates of perinatal mortality which reported 34.7 deaths per 1000 in sub-Saharan Africa ${ }^{23}$ and 77 per 1000 in South Asia, ${ }^{24}$ and to the Sustainable Development Goal target for 2030 which is 12 deaths per 1000. Those rates were estimated among births from women in the general population, but they show that our study population is at higher risk of adverse perinatal mortality. ${ }^{8}$

Few studies estimated the rate of NNM in LMIC with the definition adopted in this study. ${ }^{25} 26$ None of them provided estimates on the specific population involved in the current research. Nevertheless, the NNM rates and percentages in our study were much higher than the existing ones. ${ }^{25} 26$

Thirty-four stillbirths out of 85 (40.0\%) were fresh. These estimates are consistent with the distribution of the global burden of stillbirth as reported by the United Nations (UN). ${ }^{27}$ In its latest report, the UN raised concerns regarding some perinatal deaths, particularly stillbirths, referring to them as loss that could be avoided with improved monitoring and timely access to emergency obstetric care when required'. Indeed, some perinatal deaths, particularly intrapartum deaths (fresh stillbirth) and neonatal deaths within the first hours of life, can be prevented through improved intrapartum care for both the woman and the baby because they are linked to the access and quality of care during pregnancy and childbirth. ${ }^{27}$ In LMIC, hospitals often face a lack of skilled maternity staff who are well trained in emergency newborn care, essential drugs and the right equipment for managing neonatal conditions, including in intensive care. This significantly reduces their capacity to care for women with infection and their newborns, such as the ones from our study population. ${ }^{29} 30$

In this analysis, we estimated the likelihood of a particular birth falling into the group of NNM or perinatal death instead of the group of babies alive without severe complication based on the mother's characteristics. The main maternal factors identified in this study imply that the more complicated the mother's clinical condition, the worse her perinatal outcome. Any condition that severely affects the mother during pregnancy or immediately after childbirth can also threaten the baby's life. ${ }^{31}$ Thus, preventing or diagnosing and treating infection during pregnancy, appropriately and timely, can potentially save both the mother's and the baby's lives. ${ }^{32}$

Surprisingly, in this study, the severe maternal outcome was associated with NNM in the unadjusted analysis, but it was no longer statistically significant after adjustment. In contrast, a recent cohort study reported that newborns whose mothers had life-threatening conditions had almost 13 times higher risk of experiencing NNM. ${ }^{25}$ But that study did not include only women with infection. Second, we analysed both NNM and perinatal deaths. In studies that looked only at NNM, perinatal deaths were excluded and therefore, NNM could be overestimated. ${ }^{25}$

None of the demographic characteristics (neither the mother's age nor her education level) were associated with NNM or perinatal death. A similar pattern was found with other obstetric complications, such as pre-eclampsia. ${ }^{33}$ We believe that, in the presence of severe clinical conditions, the effect of the complication outweighs that of demographic characteristics. 
Strengths and limitations

This study could be the first to provide evidence on perinatal outcomes in the specific population of women with infection during pregnancy using data from as many as 43 LMIC. In addition, GLOSS used a standardised screening checklist and inclusion criteria to ensure that all participants across the countries were included on the same basis and a validated definition of NNM cases. Further, the awareness campaign that accompanied the GLOSS could have improved maternal infection identification and added diagnostic reliability. ${ }^{34}$

Nevertheless, NNM and perinatal death frequency could be underestimated because we stopped the babies' follow-up when the mothers were discharged. In addition, only a limited number of sociodemographic factors were assessed. Finally, we relied solely on routinely available procedures and could not confirm all cases of infections, and APO were identified based on criteria reported by healthcare providers.

\section{CONCLUSION}

Pregnancies complicated with infection can result in a high proportion of APO. Our study showed that a quarter of all births were NNM, and 1 out of 10 were perinatal deaths. In total, onethird of all births in our study population represented APO. In fetuses and infants born to women with infection during pregnancy, the severity of women's clinical condition was the main factor associated with the fact that some have 'healthy babies', while others' pregnancies end with APO. Healthcare providers and policymakers in LMIC should strengthen hospitals' readiness and capacity to prevent and timely identify maternal infections and complications. To do so, facilities should address their needs for optimal skilled staff, equipment and drug availability for good quality emergency obstetric and newborn care.

\author{
Author affiliations \\ ${ }^{1}$ Kaya Health and Demographic Surveillance System (Kaya-HDSS), Research Institute \\ of Health Sciences, Ouagadougou, Burkina Faso \\ ${ }^{2}$ UNDP/UNFPA/UNICEF/WHO/World Bank Special Programme of Research, \\ Development and Research Training in Human Reproduction (HRP), Department of \\ Sexual and Reproductive Health and Research, World Health Organization, Geneva, \\ Switzerland \\ ${ }^{3}$ Department of Obstetrics and Gynecology, School of Medicine, University of \\ Campinas, Campinas, SP, Brazil \\ ${ }^{4}$ Department of Perinatology, Mother and Child Institute, Chisinau, Moldova \\ ${ }^{5}$ Department of Obstetrics and Gynaecology, Lithuanian University of Health \\ Sciences, Kaunas, Lithuania \\ ${ }^{6}$ Maternal \& Child Morbidity \& Mortality Surveillance Unit, Family Health Bureau, \\ Colombo, Sri Lanka \\ ${ }^{7}$ Department of Obstetrics and Gynecology, School of Medicine, University of \\ Campinas, Rio de Janeiro, Brazil \\ ${ }^{8}$ George Emil Palade University of Medicine, Pharmacy, Science, and Technology of \\ Targu Mures, Targu Mures, Mures, Romania \\ ${ }^{9}$ Department of Social Medicine, Ribeirao Preto Medical School, University of Sao \\ Paulo, Sao Paulo, Brazil \\ ${ }^{10}$ Ecole docotorale ED2ST, Saint Thomas d'Aquin University (USTA), Ouagadougou, \\ Burkina Faso \\ ${ }^{11}$ Biomedical and Public Health Department, Research Institute of Health Sciences, \\ Ouagadougou, Burkina Faso
}

\section{Twitter Adama Baguiya @baguiya}

Acknowledgements The research group is very grateful to all the participating hospitals in all the countries involved in GLOSS.

Collaborators The WHO Global Maternal Sepsis Study Research group: Afghanistan: Mohammad lqbal Aman, Bashir Noormal. Argentina: Virginia Díaz, Marisa Espinoza, Julia Pasquale. Belgium: Charlotte Leroy, Kristien Roelens, Griet Vandenberghe. Benin: M Christian Urlyss Agossou, Sourou Goufodji Keke, Christiane Tshabu Aguemon. Bolivia: Patricia Soledad Apaza Peralta, Víctor Conde Altamirano, Rosalinda Hernández Muñoz. Brazil: José Guilherme Cecatti, Carolina C RibeiroDo-Valle. Burkina Faso: Vincent Batiene, Kadari Cisse, Henri Gautier Ouedraogo. Cambodia: Cheang Kannitha, Lam Phirun, Tung Rathavy. Cameroon: Elie Simo,
Pierre-Marie Tebeu, Emah Irene Yakana. Colombia: Javier Carvajal, María Fernanda Escobar, Paula Fernández. Denmark: Lotte Berdiin Colmorn, Jens Langhoff-Roos. Ecuador: Wilson Mereci, Paola Vélez. Egypt: Yasser Salah Eldin, Alaa Sultan. Ethiopia: Abdulfetah Abdulkadir Abdosh, Alula M Teklu, Dawit Worku Kassa. Ghana: Richard Adanu, Philip Govule, Charles Noora Lwanga. Guatemala: William Enrique Arriaga Romero, María Guadalupe Flores Aceituno. Honduras: Carolina Bustillo, Rigoberto Castro, Bredy Lara. India: Vijay Kumar, Vanita Suri, Sonia Trikha. Italy: Irene Cetin, Serena Donati, Carlo Personeni. Kazakhstan: Guldana Baimussanova, Saule Kabylova, Balgyn Sagyndykova. Kenya: George Gwako, Alfred Osoti, Zahida Qureshi. Kyrgyzstan: Raisa Asylbasheva, Aigul Boobekova, Damira Seksenbaeva. Lebanon: Faysal El Kak, Saad Eddine Itani, Sabina Abou Malham. Lithuania: Meilè Minkauskienė, Diana Ramašauskaitè. Malawi: Owen Chikhwaza, Luis Gadama, Eddie Malunga. Mali: Haoua Dembele, Hamadoun Sangho, Fanta Eliane Zerbo. Mexico: Filiberto Dávila Serapio, Nazarea Herrera Maldonado, Juan Ismael Islas Castañeda. Moldova: Tatiana Caraus, Ala Curteanu, Victor Petrov. Mongolia: Yadamsuren Buyanjargal, Seded Khishgee, Bat-Erdene Lkhagvasuren. Morocco: Bouchra Assarag, Amina Essolbi, Rachid Moulki. Mozambique: Nafissa Bique Osman, Zara Jaze, Arlete Mariano. Myanmar: Hla Mya Thway Einda, Thae Maung Maung, Khaing Nwe Tin. Nepal: Tara Gurung, Amir Babu Shrestha, Sangeeta Shrestha. Netherlands: Kitty Bloemenkamp Marcus J Rijken, Thomas Van Den Akker. Nicaragua: María Esther Estrada, Néstor J Pavón Gómez. Nigeria: Olubukola Adesina, Chris Aimakhu, Bukola Fawole. Pakistan: Rizwana Chaudhri, Saima Hamid, M Adnan Khan. Peru: María del Pilar Huatuco Hernández, Nelly M Zavaleta Pimentel. Philippines: Maria Lu Andal, Carolina Paula Martin, Zenaida Dy Recidoro. Romania: Mihaela-Alexandra Budianu, Lucian Pușcașiu. Senegal: Léopold Diouf, Dembo Guirassy, Philippe Marc Moreira. Slovakia: Miroslav Borovsky, Ladislav Kovac, Alexandra Kristufkova. South Africa: Sylvia Cebekhulu, Laura Cornelissen, Priya Soma-Pillay. Spain: Vicenç Cararach, Marta López, María José Vidal Benedé. Sri Lanka: Hemali Jayakody, Kapila Jayaratne, Dhammica Rowel. Sudan: Mohamed Elsheikh, Wisal Nabag, Sara Omer. Tajikistan: Victoria Tsoy, Urunbish Uzakova, Dilrabo Yunusova. Thailand: Thitiporn Siriwachirachai, Thumwadee Tangsiriwatthana. UK: Catherine Dunlop, Marian Knight, David Lissauer. Uruguay: Aquilino M Pérez, Jhon Roman, Gerardo Vitureira. Viet Nam: Dinh Anh Tuan, Luong Ngoc Truong, Nghiem Thi Xuan Hanh. Zimbabwe: Mugove Madziyire, Thulani Magwali, Stephen Munjanja. Regional Coordinators: Edgardo Abalos, Adama Baguiya, Mónica Chamillard, Bukola Fawole, Marian Knight, Seni Kouanda, Pisake Lumbiganon, Ashraf Nabhan, Ruta Nadisauskiene. Technical Advisory Group: Linda Bartlett, Fernando Bellissimo-Rodrigues, Shevin T Jacob, Sadia Shakoor, Khalid Yunis. Data management and analysis: Liana Campodónico, Cristina Cuesta, Hugo Gamerro, Daniel Giordano. WHO coordinating Unit: Fernando Althabe, Mercedes Bonet, Vanessa Brizuela, A Metin Gülmezoglu, João Paulo Souza.

Contributors $A B, M B$ and JPS conceptualised the study with inputs from the research group. $A B$ did the statistical analysis. MB, JGC, VB and SK contributed to statistical analysis, interpretation of findings and substantial input to the manuscript. $M B, J G C, V B, A C, M M, K J, C C R d V, M-A B$, JPS and SK contributed to interpreting findings and commented on all versions of the manuscript. The study group members led the acquisition of data. All members of the research group approved the final manuscript.

Funding The Global Maternal Sepsis Study (GLOSS) and Awareness Campaign were funded by the UNDP/UNFPA/UNICEF/WHO/World Bank Special Program of Research, Development and Research Training in Human Reproduction (HRP), a cosponsored program executed by the World Health Organization (WHO) (project A65787); Department of Sexual and Reproductive Health and Research, World Health Organization, Geneva, Switzerland; Merck Sharp \& Dohme Corp., a whollyowned subsidiary of Merck and Co., Inc. (Kenilworth, NJ USA), through its Merck for Mothers program and the United States Agency for International Development (USAID) Grant number GHA-G-00-09-00003.

Disclaimer The views of the funding bodies have not influenced the content of this manuscript. The named authors alone are responsible for the views expressed in this publication and do not necessarily represent the decisions or the policies of the UNDP-UNFPA-UNICEF-WHO-World Bank Special Program of Research, Development and Research Training in Human Reproduction (HRP) or the World Health Organization (WHO).

Map disclaimer The depiction of boundaries on this map does not imply the expression of any opinion whatsoever on the part of BMJ (or any member of its group) concerning the legal status of any country, territory, jurisdiction or area or of its authorities. This map is provided without any warranty of any kind, either express or implied.Note: The boundaries shown in figure 1 do not imply the expression of any opinion whatsoever on the part of WHO concerning the legal status of any country, or concerning the delimitation of its frontiers or boundaries.

Competing interests None declared.

\section{Patient consent for publication Not required.}

Ethics approval The protocol was submitted to and approved by the WHO Research Ethics Review Committee (protocol ID: A65787, approved on 08/06/2017).

Provenance and peer review Not commissioned; externally peer reviewed. 
Data availability statement Data are available on reasonable request. Individual countries own GLOSS country-level data. The WHO owns the global data used for this analysis, and they are available on request from the WHO's study coordinator in Geneva.

Supplemental material This content has been supplied by the author(s). It has not been vetted by BMJ Publishing Group Limited (BMJ) and may not have been peer-reviewed. Any opinions or recommendations discussed are solely those of the author(s) and are not endorsed by BMJ. BMJ disclaims all liability and responsibility arising from any reliance placed on the content. Where the content includes any translated material, BMJ does not warrant the accuracy and reliability of the translations (including but not limited to local regulations, clinical guidelines, terminology, drug names and drug dosages), and is not responsible for any error and/or omissions arising from translation and adaptation or otherwise.

Open access This is an open access article distributed in accordance with the Creative Commons Attribution Non Commercial (CC BY-NC 4.0) license, which permits others to distribute, remix, adapt, build upon this work non-commercially, and license their derivative works on different terms, provided the original work is properly cited, appropriate credit is given, any changes made indicated, and the use is non-commercial. See: http://creativecommons.org/licenses/by-nc/4.0/.

\section{ORCID iDs}

Adama Baguiya http://orcid.org/0000-0003-1016-4896 Mercedes Bonet http://orcid.org/0000-0001-9015-1635

José Guilherme Cecatti http://orcid.org/0000-0003-1285-8445

Vanessa Brizuela http://orcid.org/0000-0002-4860-0828

Ala Curteanu http://orcid.org/0000-0002-5311-1084

Meile Minkauskiene http://orcid.org/0000-0003-1056-0522

Carolina Carvalho Ribeiro-do-Valle http://orcid.org/0000-0002-2630-9909

João Paulo Souza http://orcid.org/0000-0002-2288-4244

Séni Kouanda http://orcid.org/0000-0003-2426-7669

\section{REFERENCES}

1 Say L, Chou D, Gemmill A, et al. Global causes of maternal death: a who systematic analysis. Lancet Glob Health 2014;2:e323-33.

2 Hug L, Alexander M, You D, et al. National, regional, and global levels and trends in neonatal mortality between 1990 and 2017, with scenario-based projections to 2030: a systematic analysis. Lancet Glob Health 2019;7:e710-20.

3 Rai SK, Kant S, Srivastava R, et al. Causes of and contributors to infant mortality in a rural community of North India: evidence from verbal and social autopsy. BMJ Open 2017;7:e012856.

4 Fottrell E, Osrin D, Alcock G, et al. Cause-Specific neonatal mortality: analysis of 3772 neonatal deaths in Nepal, Bangladesh, Malawi and India. Arch Dis Child Fetal Neonatal Ed 2015;100:F439-47.

5 Hibberd PL, Hansen NI, Wang ME, et al. Trends in the incidence of possible severe bacterial infection and case fatality rates in rural communities in sub-Saharan Africa, South Asia and Latin America, 2010-2013: a multicenter prospective cohort study. Reprod Health 2016;13:65.

6 UN Inter-agency Group for Child Mortality Estimation. Levels and trends in child mortality. New York: UNICEF, 2020. https://www.unicef.org/media/79371/file/UNIGME-child-mortality-report-2020.pdf.pdf

7 GBD 2016 Causes of Death Collaborators. Global, regional, and national age-sex specific mortality for 264 causes of death, 1980-2016: a systematic analysis for the global burden of disease study 2016. Lancet 2017;390:1151-210.

8 Vogel JP, Souza JP, Mori R, et al. Maternal complications and perinatal mortality: findings of the world Health organization multicountry survey on maternal and newborn health. BJOG 2014;121 Suppl 1:76-88.

9 Cools P, Melin P. Group B Streptococcus and perinatal mortality. Res Microbiol 2017; 168:793-801.

$10 \mathrm{He}$ W, Jin Y, Zhu H, et al. Effect of Chlamydia trachomatis on adverse pregnancy outcomes: a meta-analysis. Arch Gynecol Obstet 2020;302:553-67.

11 Bellizzi S, Bassat Q, Ali MM, et al. Effect of puerperal infections on early neonatal mortality: a secondary analysis of six demographic and health surveys. PLOS One 2017;12:e0170856.
12 Knowles SJ, O'Sullivan NP, Meenan AM, et al. Maternal sepsis incidence, aetiology and outcome for mother and fetus: a prospective study. BJOG 2015;122:663-71.

13 Duan $\mathrm{R}$, Xu X, Wang $X$, et al. Perinatal outcome in women with bacterial sepsis: a cross-sectional study from West China. Medicine 2019;98:e17751.

14 Page JM, Bardsley T, Thorsten V, et al. Stillbirth associated with infection in a diverse U.S. cohort. Obstet Gynecol 2019;134:1187-96.

15 WHO Global Maternal Sepsis Study (GLOSS) Research Group. Frequency and management of maternal infection in health facilities in 52 countries (GLOSS): a 1-week inception cohort study. Lancet Glob Health 2020;8:e661-71.

16 The World Bank. World bank country and lending groups - world bank data help desk, 2019. Available: https://datahelpdesk.worldbank.org/knowledgebase/articles/ 906519-world-bank-country-and-lending-groups [Accessed 13 Nov 2019].

17 Bonet M, Souza JP, Abalos E, et al. The global maternal sepsis study and awareness campaign (GLOSS): study protocol. Reprod Health 2018;15:16.

18 Lawn JE, Gravett MG, Nunes TM, et al. Global report on preterm birth and stillbirth (1 of 7): definitions, description of the burden and opportunities to improve data. BMC Pregnancy Childbirth 2010;10 Suppl 1:S1.

19 Blencowe $\mathrm{H}$, Cousens S, Jassir FB, et al. National, regional, and worldwide estimates of stillbirth rates in 2015, with trends from 2000: a systematic analysis. Lancet Glob Health 2016:4:e98-108.

20 Santos JP, Pileggi-Castro C, Camelo JS, et al. Neonatal near miss: a systematic review. BMC Pregnancy Childbirth 2015;15:320.

21 Pileggi-Castro C, Camelo JS, Perdoná GC, et al. Development of criteria for identifying neonatal near-miss cases: analysis of two who multicountry cross-sectional studies. BJOG 2014;121 Suppl 1:110-8.

22 Dey S, Raheem E. Multilevel multinomial logistic regression model for identifying factors associated with anemia in children 6-59 months in northeastern states of India. Cogent Mathematics 2016;3:1159798.

23 Akombi BJ, Renzaho AM. Perinatal mortality in sub-Saharan Africa: a meta-analysis of demographic and health surveys. Ann Glob Health 2019;85:106.

24 Alliance for Maternal and Newborn Health Improvement (AMANHI) mortality study group. Population-based rates, timing, and causes of maternal deaths, stillbirths, and neonatal deaths in South Asia and sub-Saharan Africa: a multi-country prospective cohort study. Lancet Glob Health 2018;6:e1297-308.

25 Tekelab T, Chojenta C, Smith R, et al. Incidence and determinants of neonatal near miss in South Ethiopia: a prospective cohort study. BMC Pregnancy Childbirth 2020;20:354.

26 de Lima THB, Katz L, Kassar SB, et al. Neonatal near miss determinants at a maternity hospital for high-risk pregnancy in northeastern Brazil: a prospective study. BMC Pregnancy Childbirth 2018;18:401.

27 United Nations Inter-agency Group for Child Mortality Estimation (UN IGME). A neglected tragedy: the global burden of stillbirths. New York: UNICEF, 2020. https:// data.unicef.org/resources/a-neglected-tragedy-stillbirth-estimates-report/

28 Edwards MS. Adverse fetal outcomes: expanding the role of infection. JAMA 2014;311:1115-6.

29 Munabi-Babigumira S, Glenton C, Lewin S, et al. Factors that influence the provision of intrapartum and postnatal care by skilled birth attendants in low- and middleincome countries: a qualitative evidence synthesis. Cochrane Database Syst Rev 2017;11:CD011558.

30 Bradley S, Kamwendo F, Chipeta E, et al. Too few staff, too many patients: a qualitative study of the impact on obstetric care providers and on quality of care in Malawi. BMC Pregnancy Childbirth 2015;15:65.

31 Zanardi DM, Parpinelli MA, Haddad SM, et al. Adverse perinatal outcomes are associated with severe maternal morbidity and mortality: evidence from a national multicentre cross-sectional study. Arch Gynecol Obstet 2019;299:645-54.

32 Goldenberg RL, McClure EM, Saleem S. Improving pregnancy outcomes in low- and middle-income countries. Reprod Health 2018;15.

33 Ayala-Ramírez P, Serrano N, Barrera V, et al. Risk factors and fetal outcomes for preeclampsia in a Colombian cohort. Heliyon 2020;6:e05079.

34 Brizuela V, Bonet M, Trigo Romero CL, et al. Early evaluation of the 'STOP SEPSIS!' WHO Global Maternal Sepsis Awareness Campaign implemented for healthcare providers in 46 low, middle and high-income countries. BMJ Open 2020;10:e036338 